Atmos. Chem. Phys., 19, 11545-11557, 2019

https://doi.org/10.5194/acp-19-11545-2019

(C) Author(s) 2019. This work is distributed under

the Creative Commons Attribution 4.0 License.

\title{
Fossil fuel combustion and biomass burning sources of global black carbon from GEOS-Chem simulation and carbon isotope measurements
}

\author{
Ling $\mathbf{Q i}^{1}$ and Shuxiao Wang ${ }^{1,2}$ \\ ${ }^{1}$ State Key Joint Laboratory of Environment Simulation and Pollution Control, School of Environment, \\ Tsinghua University, Beijing 100084, China \\ ${ }^{2}$ State Environmental Protection Key Laboratory of Sources and Control of Air Pollution Complex, Beijing 100084, China
}

Correspondence: Shuxiao Wang (shxwang @tsinghua.edu.cn)

Received: 18 January 2019 - Discussion started: 3 April 2019

Revised: 9 July 2019 - Accepted: 22 August 2019 - Published: 12 September 2019

\begin{abstract}
We identify sources (fossil fuel combustion versus biomass burning) of black carbon (BC) in the atmosphere and in deposition using a global 3-D chemical transport model GEOS-Chem. We validate the simulated sources against carbon isotope measurements of $\mathrm{BC}$ around the globe and find that the model reproduces mean biomass burning contribution $\left(f_{\mathrm{bb}} ; \%\right)$ in various regions within a factor of 2 (except in Europe, where $f_{\mathrm{bb}}$ is underestimated by $63 \%$ ). GEOS-Chem shows that contribution from biomass burning in the Northern Hemisphere $\left(f_{\mathrm{bb}}: 35 \pm 14 \%\right)$ is much less than that in the Southern Hemisphere $(50 \pm 11 \%)$. The largest atmospheric $f_{\mathrm{bb}}$ is in Africa $(64 \pm 20 \%)$. Comparable contributions from biomass burning and fossil fuel combustion are found in southern (S) Asia $(53 \pm 10 \%)$, southeastern (SE) Asia $(53 \pm 11 \%)$, S America $(47 \pm 14 \%)$, the S Pacific ( $47 \pm 7 \%$ ), Australia $(53 \pm 14 \%)$ and the Antarctic $(51 \pm 2 \%) . f_{\text {bb }}$ is relatively small in eastern Asia $(40 \pm 13 \%)$, Siberia ( $35 \pm 8 \%$ ), the Arctic ( $33 \pm 6 \%)$, Canada ( $31 \pm 7 \%$ ), the US $(25 \pm 4 \%)$ and Europe (19 $\pm 7 \%)$. Both observations and model results suggest that atmospheric $f_{\mathrm{bb}}$ is higher in summer (59\%-78\%, varying with sub-regions) than in winter $(28 \%-32 \%)$ in the Arctic, while it is higher in winter $(42 \%-58 \%)$ and lower in summer $(16 \%-42 \%)$ over the Himalayan-Tibetan Plateau. The seasonal variations of Atmospheric $f_{\text {bb }}$ are relatively flat in North America, Europe and Asia. We conducted four experiments to investigate the uncertainties associated with biofuel emissions, hygroscopicity of $\mathrm{BC}$ in fresh emissions, the aging rate and size-resolved wet scavenging. We find that doubling biofuel emissions for domestic heating north of $45^{\circ} \mathrm{N}$ increases $f_{\mathrm{bb}}$
\end{abstract}

values in Europe in winter by $\sim 30 \%$, reducing the discrepancy between observed and modeled atmospheric $f_{\mathrm{bb}}$ from $-63 \%$ to $-54 \%$. The remaining large negative discrepancy between model and observations suggests that the biofuel emissions are probably still underestimated at high latitudes. Increasing the fraction of thickly coated hydrophilic BC from $20 \%$ to $70 \%$ in fresh biomass burning plumes increases the fraction of hydrophilic BC in biomass burning plumes by $0 \%-20 \%$ (varying with seasons and regions) and thereby reduces atmospheric $f_{\text {bb }}$ by up to $11 \%$. Faster aging $(4 \mathrm{~h} e$ folding time versus $1.15 \mathrm{~d} e$-folding time) of $\mathrm{BC}$ in biomass burning plumes reduces atmospheric $f_{\text {bb }}$ by $7 \%(1 \%-14 \%$, varying with seasons and regions), with the largest reduction in remote regions, such as the Arctic, the Antarctic and the $S$ Pacific. Using size-resolved scavenging accelerates scavenging of $\mathrm{BC}$ particles in both fossil fuel and biomass burning plumes, with a faster scavenging of $\mathrm{BC}$ in fossil fuel plumes. Thus, atmospheric $f_{\mathrm{bb}}$ increases in most regions by $1 \%-14 \%$. Overall, atmospheric $f_{\mathrm{bb}}$ is determined mainly by $f_{\mathrm{bb}}$ in emissions and, to a lesser extent, by atmospheric processes, such as aging and scavenging. This confirms the assumption that $f_{\mathrm{bb}}$ in local emissions determines atmospheric $f_{\text {bb }}$ in previous studies, which compared measured atmospheric $f_{\mathrm{bb}}$ directly with local $f_{\mathrm{bb}}$ in bottom-up emission inventories. 


\section{Introduction}

Black carbon (BC) in the atmosphere and deposited over snow and ice absorbs solar radiation, triggers positive feedbacks and exerts a positive radiative forcing on the global climate (IPCC, 2014). Estimates of BC radiative forcing span a large range $\left(0.2-1 \mathrm{~W} \mathrm{~m}^{-2}\right.$; Bond et al., 2013; IPCC, 2014). One of the uncertainties lies in the predictions of $\mathrm{BC}$ vertical profiles around the globe that are different by orders of magnitude, particularly in remote regions, by chemical transport and by climate models (Samset et al., 2013, 2014). To reduce the uncertainty, in addition to the widely used BC concentration observations in the troposphere, at the surface and in snow, observation-based source apportionment (fossil fuel versus biomass burning) of $\mathrm{BC}$ provides another dimension for constraining model simulations of $\mathrm{BC}$ distribution. The optical properties of $\mathrm{BC}$ from fossil fuel and biomass burning plumes are distinctively different (Bond et al., 2013), resulting in different radiative forcing from the two sources (Jacobson, 2010). Because of the relatively short lifetime compared to greenhouse gases, accurate source apportionment of $\mathrm{BC}$ is important for short-term climate change mitigation.

Carbon isotope analysis is effective in distinguishing emissions from fossil fuel combustion (e.g., coal, oil and natural gas) and contemporary biomass burning (expressed as contribution from biomass burning, $f_{\mathrm{bb}} ; \%$ ) because fossil emissions are free of ${ }^{14} \mathrm{C}$ and biomass emissions have a characteristic ${ }^{14} \mathrm{C} /{ }^{12} \mathrm{C}$ ratio that is proportional to atmospheric carbon dioxide at the time of carbon fixation (Reddy et al., 2002). Combining $\delta^{13} \mathrm{C}$ and $\Delta^{14} \mathrm{C}$ measurements further differentiates the contribution from coal and liquid fossil fuel combustion (oil, gasoline and diesel; Andersson et al., 2015, and references therein). Fossil fuel combustion has an anthropogenic origin, including industrial use, domestic cooking and heating, and transport (Bond et al., 2007). Contemporary biomass burning can come from both anthropogenic and natural sources. The former includes mainly industrial and domestic burning of biofuels (fuelwood, charcoal, agricultural residues and dung; Fernandes et al., 2007), and the latter involves open fires of forests, crops, grass and peatlands (van der Werf et al., 2010). Carbon isotope measurements are widely used for source apportionment of $\mathrm{BC}$ in the atmosphere in southern Asia (Gustafsson et al., 2009; Budhavant et al., 2015), eastern Asia (Chen et al., 2013; Andersson et al., 2015; Zhang et al., 2015; Li et al., 2016), Europe (Szidat et al., 2006, 2009; Zhang et al., 2012) and the Arctic (Barrett et al., 2015; Winiger et al., 2015, 2016, 2017); in snow over the Himalayan-Tibetan Plateau (Li et al., 2016); and in an Alpine ice core (Jenk et al., 2006).

Previous studies (Gustafsson et al., 2009; Chen et al., 2013; Li et al., 2016) compared carbon isotope measurements directly to the $f_{\text {bb }}$ of local bottom-up emission inventories. The assumption behind these studies is that the major controlling factor of $f_{\mathrm{bb}}$ in the atmosphere is local emissions. However, BC-containing particles in fossil fuel and biomass burning plumes have distinctively different mixing states and hygroscopicities (Moteki et al., 2007; Schwarz et al., 2008; Shiraiwa et al., 2007; Akagi et al., 2012), which might further affect BC scavenging in the two kinds of plumes and thus $f_{\mathrm{bb}}$ in the atmosphere and after deposition. Li et al. (2016) found smaller contribution from fossil fuel in snow than in air, suggesting that biomass burning emissions are easier to deposit compared to fossil fuel combustion emissions. Possible factors affecting $f_{\mathrm{bb}}$ in the atmosphere and in deposition are mixing states and hygroscopicities in freshly emitted fossil fuel and biomass burning plumes, the consecutive aging rate, and scavenging. However, as far as we are aware, no study has quantified the contribution of different factors to sources in terms of global BC in the atmosphere and in deposition.

In this study, we simulate sources of BC (fossil fuel combustion versus biomass burning) using a global 3-D chemical transport model GEOS-Chem. We describe the model and the carbon isotope measurements in Sects. 2 and 3, respectively. We evaluate the model simulation of $f_{\mathrm{bb}}$ in Sect. 4.1; analyze the spatial and temporal variations of $f_{\mathrm{bb}}$ in Sect. 4.2; and evaluate the uncertainties associated with $f_{\mathrm{bb}}$ in $\mathrm{BC}$ emissions, the BC mixing state and hygroscopicity in fresh emissions, aging rage and size-resolved scavenging in Sect. 4.3.

\section{Model description}

GEOS-Chem is a global chemical transport model driven by assimilated meteorological fields from the Goddard Earth Observing System (GEOS) of the NASA Global Modeling and Assimilation Office (Bey et al., 2001). We use GEOSChem v11-01 coupled with the TwO-Moment Aerosol Sectional (TOMAS) microphysics scheme (Adams and Seinfeld, 2002). This is a state-of-the-art global model for simulating global distribution of BC (Wang et al., 2011; Qi et al., 2017a, c). We use 15 size bins ranging from $3 \mathrm{~nm}$ to $10 \mu \mathrm{m}$, with tracers for sulfate, sea salt, organic aerosols, $\mathrm{BC}$ and dust (Pierce et al., 2007; Lee et al., 2009; D'Andrea et al., 2013; Kodros and Peirce, 2017). Modern-Era Retrospective analysis for Research and Applications, Version 2 (MERRA2), meteorological data sets are used to drive model simulation at $4^{\circ}$ latitude $\times 5^{\circ}$ longitude horizontal resolution and 47 vertical layers from the surface to $0.01 \mathrm{hPa}$. Global fossil fuel and biofuel combustion emissions of $\mathrm{BC}$ are from Bond et al. (2007) and Fernandes et al. (2007), respectively. We also include gas flaring emissions from Stohl et al. (2013). We use data of BC emissions in Asia by Li et al. (2017). We apply seasonal variations for domestic heating emissions based on the degree-day concept (Stohl et al., 2013; Qi et al., 2017c). We use daily open fire emissions from the Global Fire Emissions Database version 4 (GFED4; Giglio et al., 2013) in this study. We assume $20 \%$ of the freshly emitted BC aerosols to be thickly coated and hydrophilic (Park et al., 2003). We assume that hydrophobic BC is converted to hydrophilic BC 
with an $e$-folding time of $1.15 \mathrm{~d}$ (Park et al., 2005). Wet deposition follows Liu et al. (2001), with updates of below-cloud scavenging efficiency and in-cloud scavenging in ice clouds in Wang et al. (2011) and updates of BC scavenging in mixphase clouds in Qi et al. (2017a).

\section{Observation data}

To our knowledge, carbon isotope analysis of BC sources in the atmosphere is available at 65 sites across the globe in different seasons (Table S1 and Fig. S3 in the Supplement). Generally, $f_{\text {bb }}$ values are larger in remote regions $(36 \pm 16 \%$ in southern Asia, $33 \pm 14 \%$ in the Arctic and $39 \pm 17 \%$ over the Himalayan-Tibetan Plateau) than those in urban regions (13 $\pm 4 \%$ in North America), indicating a larger contribution from biofuel and open fires in rural, developing and remote regions. In addition, $f_{\mathrm{bb}}$ values strongly depend on seasons (see detailed analysis in Sect. 4.2.1). Carbon isotope measurements of BC in snow are only available over the Tibetan Plateau from Li et al. (2016).

The isotope mass balance equation based on the $\Delta^{14} \mathrm{C}$ $\left({ }^{14} \mathrm{C} /{ }^{12} \mathrm{C}\right)$ data was applied to apportion the relative contributions to atmospheric $\mathrm{BC}$ from biomass burning of modern carbon $\left(f_{\mathrm{bb}}\right)$ and fossil fuel combustion:

$\Delta{ }^{14} \mathrm{C}=\Delta{ }^{14} \mathrm{C}_{\mathrm{bb}} f_{\mathrm{bb}}+\Delta^{14} \mathrm{C}_{\mathrm{ff}}\left(1-f_{\mathrm{bb}}\right)$,

where $\Delta^{14} \mathrm{C}$ is the measured radiocarbon content of the $\mathrm{BC}$ component and $\Delta^{14} \mathrm{C}_{\mathrm{ff}}$ is $-1000 \%$ by definition because fossil carbon is completely depleted in radiocarbon ( $\mathrm{Li}$ et al., 2016). $\Delta^{14} \mathrm{C}_{\mathrm{bb}}$ endmembers used in this equation are usually between $+70 \%$ and $+225 \%$, depending on the type and age of the burned biomass (Winiger et al., 2015; Barrett et al., 2015; Li et al., 2016). The former value corresponds to freshly produced biomass, such as crop and grass. The latter value reflects the burning of wood, which has accumulated over a life span that is decades to centuries long. A different choice of the $\Delta^{14} \mathrm{C}_{\mathrm{bb}}$ endmember is one of the uncertainties associated with this source apportionment method. The uncertainty of $\pm 25 \%$ o translates to $<5 \%$ in the resulting $f_{\text {bb }}$ estimate (Winiger et al., 2016). Another uncertainty stems from the method of isolating BC from total carbon in sampled particles, as described by Zhang et al., 2012. They found that the isolation method prior to thermal treatments, thermal-optical methods and the heating protocols is important to the isolation of $\mathrm{BC}$ and organic carbon and the following isotope analysis. They found that different protocols of the thermal-optical method lead to a $\sim 30 \%$ difference of estimated $f_{\text {bb }}$ values.

\section{Results and discussions}

GEOS-Chem captures the probability density function (PDF) of annual BC concentrations at sites in the US, Europe,
China and the Arctic (see site description in Qi et al., 2017b) but overestimates the frequency of low BC concentrations (Fig. S1a). About $30 \%$ of the simulated annual BC concentration in air is underestimated by a factor of 2 (Fig. S1b). The model reproduces the PDF of BC concentration in snow preferably (correlation coefficient $r=0.98$; Fig. S2a). The simulated median BC concentrations in snow in various regions agree with observations within a factor of 2, except in the region NC_Northeast Border (Fig. S2b), where the model overestimates the observed $\mathrm{BC}$ concentration in snow by a factor of 3 due to the overestimate of local emissions in that region (Qi et al., 2017b).

\subsection{Contribution of biomass burning to $\mathrm{BC}$ in various regions}

The GEOS-Chem-simulated mean atmospheric $f_{\mathrm{bb}}$ in each region agrees with observations within a factor of 2 , except in Europe, where $f_{\mathrm{bb}}$ is underestimated by $63 \%$ (Fig. 1a). The low bias of $f_{\mathrm{bb}}$ in Europe occurs in non-summer seasons (observation: $45 \%$; model: $13 \%$ ), which is partly due to the underestimate of biofuel combustion for domestic heating by Fernandes et al. (2007) in most of the European regions during cold seasons (Herich et al., 2011). In southern (S) Asia, mean atmospheric $f_{\mathrm{bb}}$ is overestimated by $50 \%$, mostly from the $90 \%$ overestimate of $f_{\mathrm{bb}}$ at Delhi (observation: $28 \%$; model: $52 \%$ ). At this site, atmospheric $f_{\mathrm{bb}}$ values in spring and summer are overestimated by $100 \%$ and $200 \%$, respectively. In North America, the model overestimates $f_{\mathrm{bb}}$ at Salt Lake City (SLC) and Mexico City by a factor of 2. Possible reasons for the overestimate are explained in Sect. 4.2.1. In the Arctic and eastern (E) Asia, the model reproduces the observed $f_{\text {bb }}$ values within $3 \%$ and $7 \%$, respectively. In addition, GEOS-Chem underestimates the large variations of $f_{\text {bb }}$ values (horizontal lines in Fig. 1a) in every region (except in the Arctic) due to the coarse horizontal and vertical resolutions.

Over the Himalayan-Tibetan Plateau, observations show that biomass burning dominates $\mathrm{BC}$ deposited in snow (64\%), but its contribution in the atmosphere is much less (39\%; Li et al., 2016). GEOS-Chem reproduces the average $f_{\text {bb }}$ in snow (model: $63 \%$ ) but overpredicts the average atmospheric $f_{\text {bb }}$ (model: $62 \%$ ) by $56 \%$. GEOS-Chem-simulated $f_{\mathrm{bb}}$ values of BC deposition in snow at all sites over the Himalayan-Tibetan Plateau agree with observations within $40 \%$ during both monsoon (June-August) and non-monsoon seasons (Fig. 1b), suggesting that the model captures the spatial and temporal variations of $f_{\mathrm{bb}}$ in $\mathrm{BC}$ deposition in this region. The overestimate of the atmospheric $f_{\mathrm{bb}}$ is mainly from the $130 \%$ overestimate of $f_{\mathrm{bb}}$ during the monsoon season (observation: $29 \%$; model: $67 \%$ ). Possible reasons for the overestimate are discussed in Sect. 4.2.1. 

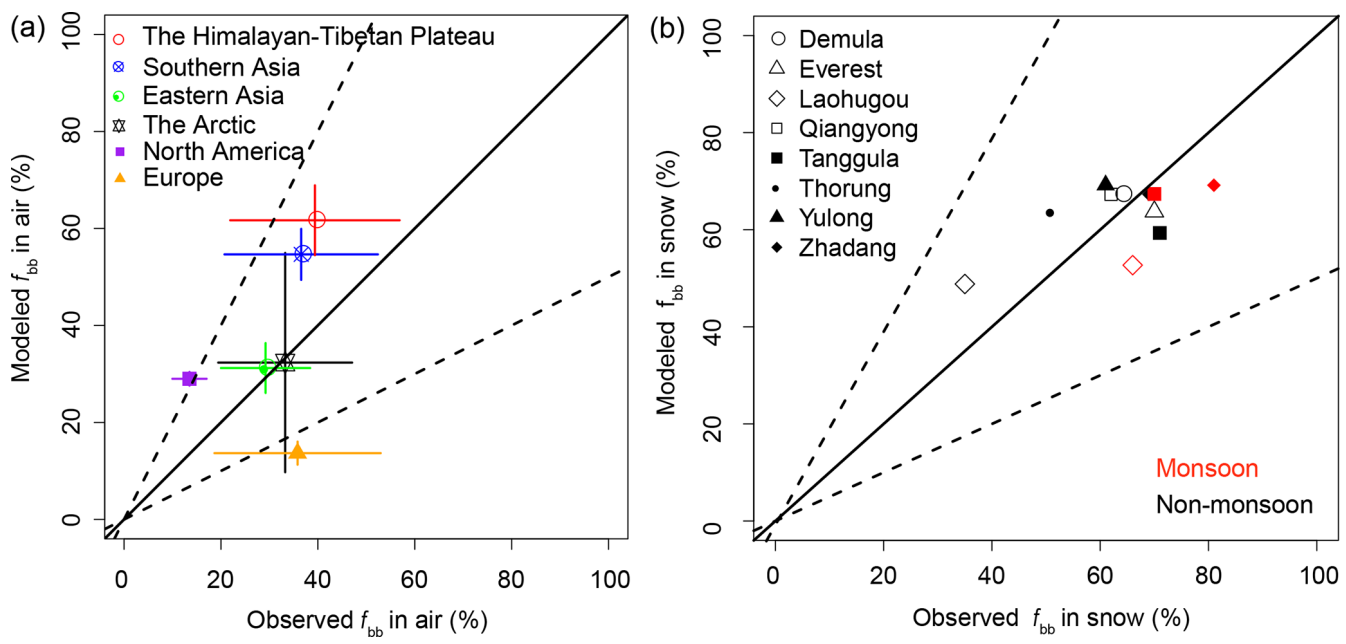

Figure 1. Observed and GEOS-Chem-simulated fraction of biomass burning $\left(f_{\mathrm{bb}} ; \%\right)$ of (a) BC in the atmosphere in the Arctic, southern Asia, North America, Europe, eastern Asia and the Himalayan-Tibetan Plateau (the regions are symbol and color coded; see data in Table S2) and (b) BC in snow during monsoon (red) and non-monsoon (black) seasons over the Himalayan-Tibetan Plateau. Also shown in panel (a) are the standard deviations of observed and model simulated $f_{\mathrm{bb}}$ in each region, reflecting the temporal and spatial variations of $f_{\mathrm{bb}}$ in the region (horizontal and vertical lines). Observations of $f_{\mathrm{bb}}$ in the atmosphere in panel (a) are from carbon isotope analysis as listed in Table S1. Observations of $f_{\mathrm{bb}}$ in BC in snow in panel (b) are from Li et al. (2016). Solid lines in panels (a) and (b) are $1: 1$ ratio lines, and dashed lines are $1: 2$ (or $2: 1$ ) ratio lines.

\subsection{Temporal and spatial variations of $f_{\mathrm{bb}}$ in different regions}

\subsubsection{Temporal variation of $f_{\mathrm{bb}}$}

In the Arctic at Abisko, observed $f_{\mathrm{bb}}$ ranges from the fall and wintertime low of $31 \%$ to the summer high of $59 \%$ (Fig. 2a) due to the large contribution from open fires in Europe in summer (Winiger et al., 2016). The model also shows a peak in $f_{\mathrm{bb}}$ in summer, but the seasonal variation is relatively flat (from $23 \%$ in winter to $27 \%$ in summer). We attribute the discrepancy to two reasons. First, $f_{\mathrm{bb}}$ values of emissions at the site lack seasonal variations, as shown in Fig. 2a. Second, the coarse resolution does not solve the vortex structure of the low-pressure and frontal systems, which is important for poleward transport of BC (Ma et al., 2014; Sato et al., 2016). At Barrow (Fig. 2b), observed $f_{\mathrm{bb}}$ values show two peaks in summer $(34 \%)$ and winter $(37 \%)$, while modeled $f_{\mathrm{bb}}$ shows a single strong peak in summer $(78 \%)$. In summer, the magnitude and variations of $f_{\mathrm{bb}}$ in the atmosphere are similar to those of $f_{\mathrm{bb}}$ in local emissions, suggesting that the atmospheric $f_{\mathrm{bb}}$ is largely determined by local emissions. The $129 \%$ overestimate of $f_{\mathrm{bb}}$ is largely due to the overestimate of local open burning emissions. In spring, fall and winter, the modeled atmospheric $f_{\text {bb }}$ values are much larger than the $f_{\mathrm{bb}}$ of local emissions, indicating a large contribution from long-range transport.

In contrast to the seasonal cycles of $f_{\mathrm{bb}}$ at sites in the Arctic, at Bode (Fig. 2c) over the Himalayan-Tibetan Plateau, $f_{\mathrm{bb}}$ values are the lowest in summer (observation: 17\%) and highest in winter (observation: $42 \%$; Li et al., 2016). The similar trend is observed at Lumbini (Fig. 2d), only with smaller amplitude (summer low: $42 \%$; spring high: $58 \%$; Li et al., 2016). The lower $f_{\mathrm{bb}}$ in summer is because of several reasons. First, less biofuel is consumed for domestic heating in warmer seasons ( $\mathrm{Li}$ et al., 2016). Second, the region is barely affected by open fires. Third, biomass-sourced BC is removed more efficiently by the frequent precipitation in summer both over the Himalayan-Tibetan Plateau and over the surrounding source regions, such as India and eastern Asia ( $\mathrm{Li}$ et al., 2016). The GEOS-Chem-simulated atmospheric $f_{\mathrm{bb}}$ values of $\mathrm{BC}$ at all sites over the HimalayanTibetan Plateau (results for Bode and Lumbini are shown in Fig. $2 c$ and d, and the others are not shown) have weak or no seasonal variations. In addition, the model does not capture the observed increasing trend of $f_{\mathrm{bb}}$ along the Mustang Valley and Langtang Valley. Possible reasons for the discrepancies are many. First, the $f_{\mathrm{bb}}$ values of local emissions have no seasonal variations, as shown in Fig. $2 \mathrm{c}$ and d. Second, it is conceivable that the coarse model resolution of global models does not reproduce the complex topography and transport pathways of BC over the Himalayan-Tibetan Plateau (He et al., 2014). However, the mean modeled atmospheric $f_{\text {bb }}$ generally agrees with observations (within $60 \%$ ), and the modeled atmospheric $f_{\mathrm{bb}}$ generally follows the $f_{\mathrm{bb}}$ of local emissions across the whole plateau. These comparisons suggest that the atmospheric $f_{\mathrm{bb}}$ over the Himalayan-Tibetan Plateau is largely determined by $f_{\mathrm{bb}}$ in emissions in the region.

At the SLC (North America; Fig. 2e), Tokyo (eastern Asia; Fig. 2f), Maldives Climate Observatory in Hanimaadhoo (MCOH) and Indian Institute of Tropical Meteorology 

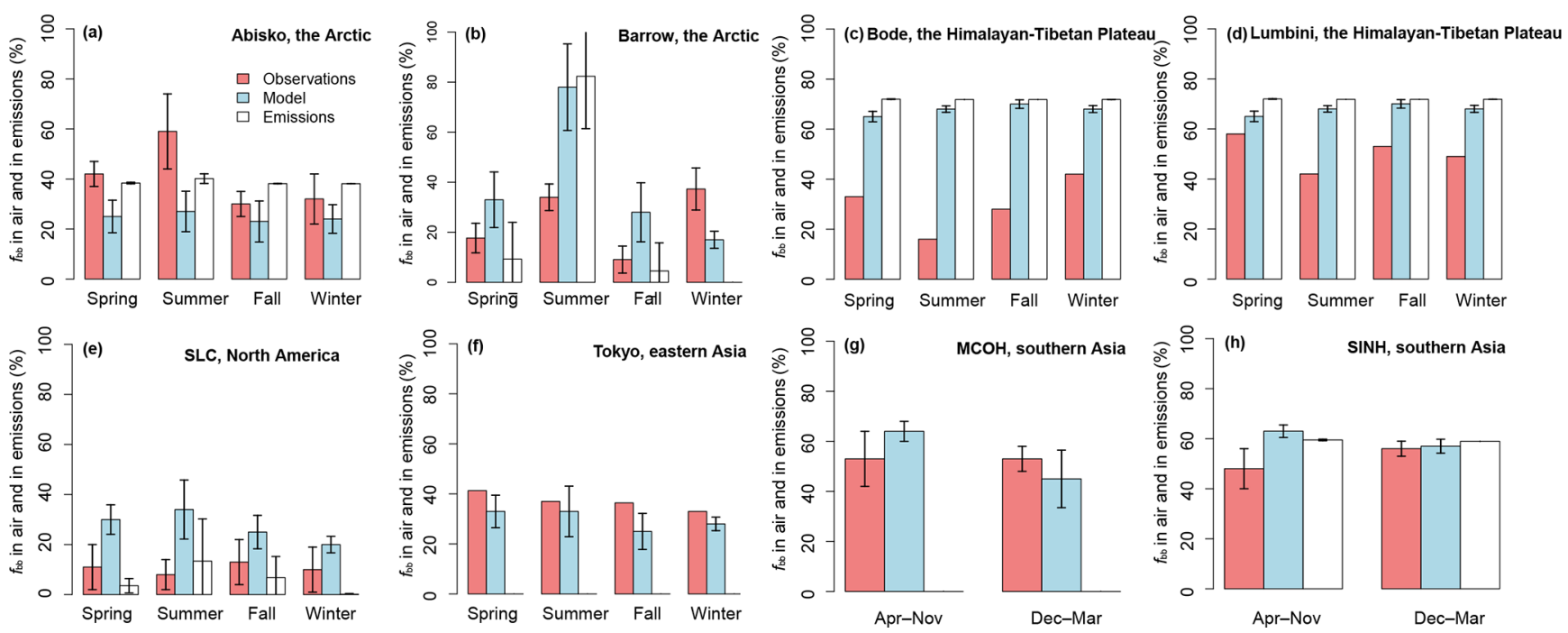

Figure 2. Seasonal variations of observed (light coral bars) and GEOS-Chem-simulated (light blue bars) $f_{\mathrm{bb}}$ of BC in the atmosphere at (a) Abisko and (b) Barrow in the Arctic, (c) Bode and (d) Lumbini over the Himalayan-Tibetan Plateau, (e) Salt Lake City in North America, (f) Tokyo in eastern Asia, and (g) $\mathrm{MCOH}$ and (h) SINH in southern Asia. The white bars are $f_{\mathrm{bb}}$ values of BC emissions in the model grid $\left(4^{\circ}\right.$ lat $\times 5^{\circ}$ lon) of each site. Also shown are the standard deviations (error bars). Site locations are shown in Fig. S3.

in Sinhagad, India (SINH; southern Asia, Fig. 2g and h), sites, no big differences of $f_{\mathrm{bb}}$ among seasons were observed (SLC: $8 \%-13 \%$; Tokyo: $33 \%-41 \%$; MCOH: $52 \%-$ $53 \%$; SINH: $48 \%-56 \%$ ). However, BC concentrations show strong seasonal variations at the four sites, with high loadings in winter and low loadings in summer (Mouteva et al., 2017; Yamamoto et al., 2007; Budhavant et al., 2015). At SLC, the most significant local sources of $\mathrm{PM}_{2.5}$ particles are mobile emissions, which are relatively stable through the whole year (Mouteva et al., 2017). The second most important source is non-mobile sources with solid burning, mostly wood burning, which is not allowed to be used when air quality forecasts predict an inversion period (Mouteva et al., 2017). This restriction limits the extra use of solid fuels in winter, and thus limits their effects on $\mathrm{BC}$ concentrations and $f_{\mathrm{bb}}$ in the atmosphere. So the higher concentration of $\mathrm{BC}$ in winter in SLC is largely determined by the low boundary-layer height (Mouteva et al., 2017). The model overestimates $f_{\text {bb }}$ at SLC in all seasons by a factor of 2-4 (Fig. 2e). As described in Mouteva et al. (2017), the observations were in an urban environment with strong influence from local emissions. However, modeled $f_{\mathrm{bb}}$ in the atmosphere is much higher than the $f_{\mathrm{bb}}$ values of local emissions based on emission inventories in this study (Sect. 2), suggesting that the modeled atmospheric $f_{\mathrm{bb}}$ at the site is largely affected by the surrounding regions. The misrepresentation of the source region (local versus regional) is probably one reason for the large bias of modeled $f_{\mathrm{bb}}$ against observations. At the Tokyo site in eastern Asia, the model reproduces both the magnitude and the seasonal variations of observed $f_{\mathrm{bb}}$. The much lower $f_{\mathrm{bb}}$ value in emissions than in the atmosphere also indicates a regional effect. In southern Asia, GEOS-Chem reproduces the similar observed high $f_{\mathrm{bb}}$ values at $\mathrm{MOCH}$ (summer: $52 \%$; winter: $53 \%$ ) and SINH (summer: 48; winter: $56 \%$ ) within $30 \%$. However, reasons for the high $f_{\mathrm{bb}}$ values at the two sites are different. Since there are no local emissions at $\mathrm{MCOH}, f_{\mathrm{bb}}$ at the site is largely affected by long-range transport. In contrast, $f_{\mathrm{bb}}$ in the atmosphere follows $f_{\mathrm{bb}}$ in local emissions at SINH, suggesting that the atmospheric $f_{\mathrm{bb}}$ at the site is mostly affected by local emissions. At $\mathrm{MCOH}$ the high $f_{\mathrm{bb}}$ is probably from the large $f_{\mathrm{bb}}$ in the outflow of Africa, while at SINH local burning of agricultural crop residues is the major source (Budhavant et al., 2015).

\subsubsection{Spatial variation of modeled $f_{\mathrm{bb}}$}

GEOS-Chem suggests that the Southern Hemisphere has a higher contribution from biomass burning both for BC in surface air $(50 \pm 11 \%)$ and in deposition $(53 \pm 10 \%$, Fig. 3a and b). The high $f_{\mathrm{bb}}$ values in S America and Australia are largely from active open fires (accounting for $48 \%$ and $81 \%$ of the total biomass burning contributions, respectively), while in Africa biofuel consumption is the major biomass burning source (model: $64 \pm 20 \%$; Fig. $3 \mathrm{c}$ and d). Because of the strong seasonal variations of open fire emissions, the highest $f_{\mathrm{bb}}$ values in Africa, S America, the S Pacific, Australia and the Antarctic usually occur during September to November $(58 \%-71 \%)$, and the lowest values are in MarchMay (32\%-56\%; Fig. S4).

In the Northern Hemisphere, the largest $f_{\mathrm{bb}}$ values of both $\mathrm{BC}$ in the atmosphere $(93 \pm 5 \%)$ and in deposition $(92 \pm 6 \%)$ are in northern Congo, where biomass burning contribution dominates over fossil fuel emissions. southern Asia also shows large $f_{\mathrm{bb}}$ values (54\% for $\mathrm{BC}$ in air and in deposition) 
(a) Surface atmosphere

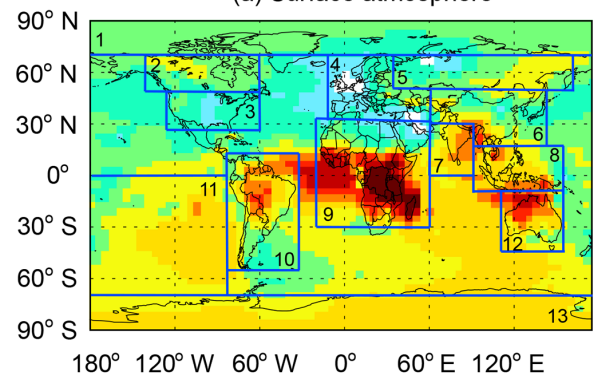

(c) Fraction of biofuel emissions

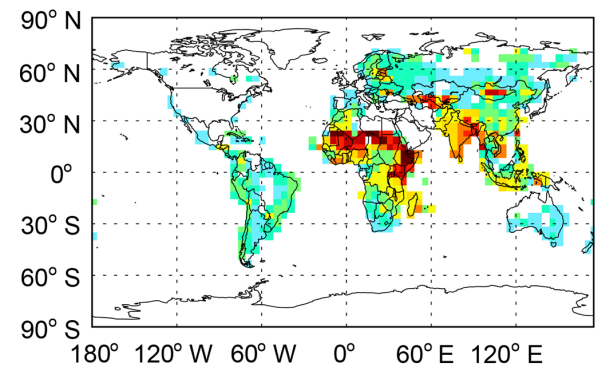

(b) Deposition

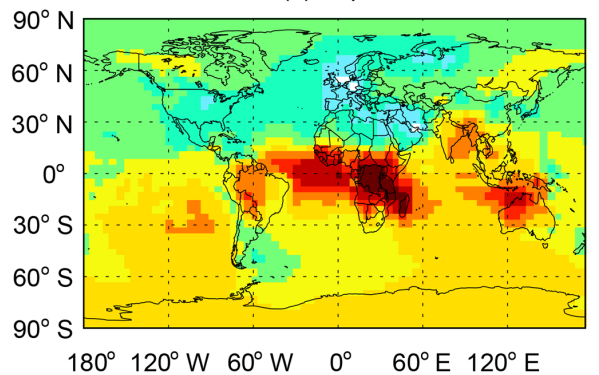

(d) Fraction of open fire emissions

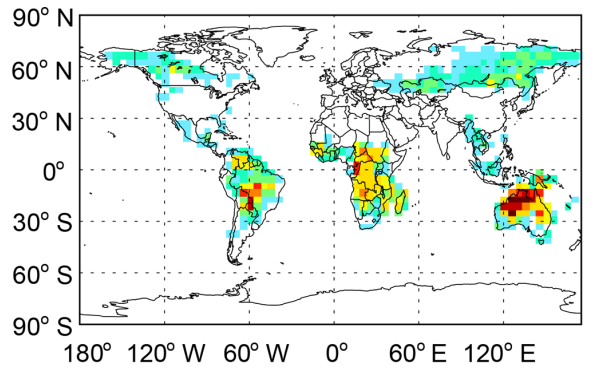

$\begin{array}{llllllllllll}0 & 10 & 20 & 30 & 40 & 50 & 60 & 70 & 80 & 90 & 100 & \%\end{array}$

Figure 3. Annual (a) $f_{\mathrm{bb}}$ of $\mathrm{BC}$ in the atmosphere at surface, (b) $f_{\mathrm{bb}}$ of $\mathrm{BC}$ deposition, (c) fraction of biofuel emissions and (d) fraction of open fire emissions. Data are averaged for 2007-2013. Also shown in panel (a) are regions discussed in the text: the Arctic (1), Canada (2), the US (3), Europe (4), Siberia (5), eastern (E) Asia (6), southern (S) Asia (7), southeastern (SE) Asia (8), Africa (9), S America (10), S Pacific (11), Australia (12) and the Antarctic (13).

due to large biofuel consumption. In other regions, such as Europe, Canada, the US, Siberia and the Arctic, fossil fuel contribution $(65 \%-80 \%)$ is much larger than biomass burning. $f_{\mathrm{bb}}$ values of $\mathrm{BC}$ in air and in deposition in different regions have different seasonal variations (Figs. S4-S5). Atmospheric $f_{\mathrm{bb}}$ values in Canada, Siberia, the Arctic and the Antarctic have the strongest seasonal variations, with a peak in summer $(49 \%-70 \%)$ because of the large fraction of open fire emissions (Figs. S6-S7). In the US, southern Europe, eastern Asia and southern Asia, seasonal variation of $f_{\mathrm{bb}}$ is relatively flat, which is also shown by observations at a few sites (Fig. 2).

\subsection{Uncertainty analysis}

Atmospheric $f_{\mathrm{bb}}$ is determined not only by emissions (fossil fuel combustion versus biomass burning) but also by atmospheric processes that affect the deposition during transport. We investigate the uncertainties associated with biofuel emissions, $f_{\mathrm{bb}}$ in fresh emissions, the $\mathrm{BC}$ aging rate and sizeresolved scavenging. We used relative change $(r ; \%)$ to describe the change of $f_{\mathrm{bb}}$ in each experiment (Exp.) relative to the standard simulation:

$r=\left(\left[f_{\mathrm{bb}}\right]_{\text {Exp. }}-\left[f_{\mathrm{bb}}\right]_{\mathrm{Std} .}\right) /\left[f_{\mathrm{bb}}\right]_{\mathrm{Std} .}$, where $r$ is the relative change, $\left[f_{\mathrm{bb}}\right]_{\text {Exp. }}$ is $f_{\mathrm{bb}}$ in each experiment and $\left[f_{\mathrm{bb}}\right]_{\mathrm{Std}}$. is the $f_{\mathrm{bb}}$ in the standard simulation in each region.

\subsubsection{Uncertainty associated with biofuel emissions}

Biofuel emission estimates are associated with large uncertainties (Fernandes et al., 2007). Source apportionment of BC in Europe based on multi-wavelength aethalometer measurements showed that $f_{\mathrm{bb}}$ in winter $(24 \%-33 \%)$ is much higher than that in summer ( $2 \%-10 \%)$, suggesting that wood burning for domestic heating increases the $f_{\mathrm{bb}}$ value in the atmosphere in winter significantly (Herich et al., 2011). In addition, Winiger et al. (2017) analyzed $f_{\mathrm{bb}}$ based on carbon isotope measurements at Tiksi in Russia and suggested that domestic use ( $\sim 60 \%$ of which is from biomass burning) accounted for $35 \%$ of $\mathrm{BC}$ at the site, following transport $(38 \%)$. We find that during the cold season, mean $f_{\mathrm{bb}}$ values in Europe and the Arctic (most sites are north of $45^{\circ} \mathrm{N}$; Table S1) are underestimated by $68 \%$ and $50 \%$ in the standard simulation, probably due to the underestimate of domestic heating in winter. However, in eastern Asia (all sites are south of $45^{\circ} \mathrm{N}$ ), mean $f_{\mathrm{bb}}$ in winter is overestimated by $22 \%$. Thus, we doubled biofuel emissions from domestic heating north of $45^{\circ} \mathrm{N}$ during cold seasons in Experiment A (Exp. A) to investigate the uncertainty associated with biofuel emis- 
sions. It is conceivable that the largest effects occur in the northern four regions, including Europe, Siberia, Canada and

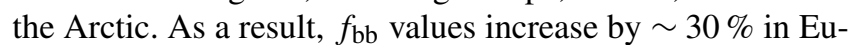
rope, Siberia and the Arctic and by $15 \%$ in Canada in winter, which is larger than those in spring and fall (4\%-13\%; Fig. 4). Consequently, the low bias of $f_{\mathrm{bb}}$ in Europe is reduced from $-63 \%$ to $-54 \%$. This improvement suggests that the biofuel emissions at high latitudes in the Northern Hemisphere are probably too low in current bottom-up BC emission inventories, supporting previous estimates (Herich et al., 2011).

\subsubsection{Uncertainty associated with hygroscopicity of BC in freshly emitted biomass burning plumes}

Recent measurements find that in freshly emitted fossil fuel plumes, the fraction of thickly coated hydrophilic BC is $\sim 10 \%$ (Moteki et al., 2007; Schwarz et al., 2008; Shiraiwa et al., 2007), while in biomass burning plumes the fraction reaches up to $70 \%$ (Schwarz et al., 2008; Akagi et al., 2012). The higher hygroscopicity of BC in freshly emitted biomass burning plumes enhances the subsequent wet scavenging rate and thereby reduces $f_{\mathrm{bb}}$ in the atmosphere. In the standard simulation, we assume that $20 \%$ of freshly emitted BC particles are hydrophilic. We investigate the effects of the initial hygroscopicity of $\mathrm{BC}$ in fresh emissions on atmospheric $f_{\mathrm{bb}}$ of $\mathrm{BC}$ in Exp. B by assuming that $70 \%$ of freshly emitted $\mathrm{BC}$ particles from biomass burning are thickly coated and hydrophilic. The resulting fraction of hydrophilic BC in biomass burning plumes in the 12 regions increases by $0 \%-20 \%$ (varying with seasons and regions), lowering $f_{\mathrm{bb}}$ in the atmosphere by up to $11 \%$ in Canada in summer. The largest reduction of $f_{\mathrm{bb}}$ shows in June-August ( $-7 \%$ averaged for all regions; Fig. 4), when open fires are frequent and active globally (Giglio et al., 2013; van der Werf et al., 2010). During this time, the largest reductions are in Canada $(-11 \%)$ and Siberia $(-10 \%)$, where the fraction of hydrophilic BC in biomass burning plumes increases by a large fraction $(11 \%-13 \%)$. In the $\mathrm{S}$ Pacific, the reduction of $f_{\mathrm{bb}}$ is large $(-10 \%)$ as well because large precipitation $\left(28 \mathrm{~kg} \mathrm{~m}^{-2}\right.$ month $\left.^{-1}\right)$ over this region removes more biomass burning BC particles in the outflow of $\mathrm{S}$ America. During September-November, the relative reduction of $f_{\mathrm{bb}}$ in the Northern Hemisphere $(-6 \%)$ is much larger than that in the Southern Hemisphere $(-1 \%)$ because $f_{\mathrm{bb}}$ values in the Southern Hemisphere are too large (Fig. S5). The changes of $f_{\text {bb }}$ values in other seasons in all regions are marginal.

\subsubsection{Uncertainty associated with $\mathrm{BC}$ aging time}

Mixing organic and inorganic particles with larger hygroscopicity, BC particles become more hydrophilic during the aging process (Bond et al., 2013). It is assumed that BC particles are converted from hydrophobic to hydrophilic with an $e$-folding time of $1.15 \mathrm{~d}$ after emission in the standard simu- lation (Park et al., 2005). However, observations showed that the fraction of thickly coated hydrophilic BC in urban fossil fuel plumes increases linearly with plume age $\left(0.5 \% \mathrm{~h}^{-1}-\right.$ $2.3 \% \mathrm{~h}^{-1}$, Moteki et al., 2007; Shiraiwa et al., 2007; Subramanian et al., 2010; McMeeking et al., 2011), while BC aging follows a logarithmic trend with an $e$-folding time of $4 \mathrm{~h}$ in biomass burning plumes (Akagi et al., 2012). The aging rates differ among plumes because of different $\mathrm{BC}$ sizes, co-emitted hygroscopic materials and oxidation capacities of the plumes (Bond et al., 2013). Thus, in Exp. C, we assume that fossil fuel combustion generated $\mathrm{BC}$ ages linearly with a rate of $1 \% \mathrm{~h}^{-1}$, while $\mathrm{BC}$ from biomass burning plumes ages with an $e$-folding time of $4 \mathrm{~h}$. This means that the fossil fuel plumes age slower than the standard simulation and are scavenged slower, while the biomass burning plumes age much faster and are removed from the atmosphere faster in precipitation. This aging scheme leads to a $0 \%-24 \%$ increase in the fraction of hydrophilic BC in the atmosphere, which reduces $f_{\mathrm{bb}}$ by up to $-14 \%$. The largest reduction of $f_{\mathrm{bb}}$ is in the S Pacific in fall (MAM) and summer (DJF) in the Southern Hemisphere, followed by the Antarctic (-12\%) during MAM and the Arctic $(-11 \%)$ during SON. The reduction of $f_{\mathrm{bb}}$ is larger in remote regions and smaller in source regions because it takes time for the different aging rates in fossil fuel and biomass burning plumes to affect the hygroscopicities of $\mathrm{BC}$ in the two plumes and the subsequent aging rates.

\subsubsection{Uncertainty associated with size-resolved scavenging}

BC particles emitted from biomass burning plumes are usually larger in size and thicker in coating thickness (Schwarz et al., 2008; Sahu et al., 2012), suggesting an easier removal from the atmosphere. For example, observations (Schwarz et al., 2008; Sahu et al., 2012) showed that the mass median diameter of BC particles in biomass burning plumes is $193 \mathrm{~nm}$ with a coating thickness of $65 \mathrm{~nm}$, while in fossil fuel plumes, the mass median diameter and coating thickness are 175 and $20 \mathrm{~nm}$. In addition, because of the different coating materials, hygroscopicities of BC-containing particles in the two kinds of plumes are different as well. The coating materials of $\mathrm{BC}$ in urban plumes are dominated by sulfate and followed by nitrate and primary and secondary organics (Shiraiwa et al., 2007), while in biomass burning plumes, the major coating materials are organics (Sahu et al., 2012). For ambient air, characteristic $\kappa$ values of organics and inorganics are $0.1(0.01-0.5)$ and $0.7(0.5-1.4$; Petters and Kreidenweis, 2007; Gunthe et al., 2011, and references therein). Higher hygroscopicity of BC in fossil fuel plumes suggests that they are easier to activate and serve as cloud condensation nuclei (CCNs) compared to BC particles in biomass burning plumes. The higher hygroscopicity and smaller size of BC particles in fossil fuel plumes have the opposite effect on their removal rate. Thus, we investigate the total effects of size-resolved scavenging in Exp. D; we use 



Figure 4. GEOS-Chem-simulated fractional change $(r)$ to atmospheric $f_{\text {bb }}$ relative to the standard simulation, as a result of doubled biofuel emissions north of $45^{\circ} \mathrm{N}$ (Exp. A), $70 \%$ of hydrophilic BC in freshly emitted biomass burning BC-containing particles (Exp. B), $4 \mathrm{~h} e$ folding aging time of $\mathrm{BC}$ in biomass burning plumes and linear aging rate of $1 \%$ in fossil fuel plumes (Exp. C), TOMAS microphysical aging and scavenging (Exp. D), and finer horizontal model resolution $\left(2^{\circ}\right.$ lat $\times 2.5^{\circ}$ lon; Exp. E), $r=\left(\left[f_{\mathrm{bb}}\right]_{\text {Exp. }}-\left[f_{\mathrm{bb}}\right]_{\text {Std. }}\right) /\left[f_{\mathrm{bb}}\right]_{\text {Std. }}$, which $_{\text {B }}$ varies with regions (see region definition in Fig. 3a) and seasons (a: March-May - MAM; b: June-August - JJA; c: September-November SON; d: December-February - DJF), averaged for 2007-2013. See details of the standard simulation and the uncertainty experiments in the text.

the TOMAS microphysics scheme to process the aging and wet scavenging of $\mathrm{BC}$ with different sizes from fossil fuel combustion and biomass burning. The mass median diameters of fossil fuel and biomass burning BC particles are assumed to be 160 and $200 \mathrm{~nm}$, respectively. Size-resolved coagulation, condensation, nucleation and cloud processing are implemented. Coating materials included are sulfate, nitrate, sea-salt, organics and mineral dust. The size-resolved aging and scavenging scheme leads to a larger increase in the fraction of hydrophilic BC in fossil fuel plumes (by $16 \%$; $0 \%-$ $31 \%$, varying with regions) than in biomass burning plumes (by $12 \% ; 0 \%-23 \%$ ). This increase in both fossil fuel and biomass burning plumes suggests that $\mathrm{BC}$ particles are removed faster in the size-resolved simulation than in the standard simulation with a bulk removal parameterization. The larger increase in the fraction of hydrophilic BC in fossil fuel plumes means that $\mathrm{BC}$ in fossil fuel plumes is removed faster than that in biomass burning plumes in the size-resolved simulation. This is probably because the total effect of higher hygroscopicity of coating materials and smaller size of $\mathrm{BC}$ in fossil fuel plumes enhances their removal. Thus atmospheric $f_{\text {bb }}$ increases in most regions during MAM (by 1\%-14\%), SON (by $0 \%-7 \%$ ) and DJF (by 1\%-12\%). The most noticeable characteristic is that the increase in $f_{\mathrm{bb}}$ in the Northern
Hemisphere is larger than that in the Southern Hemisphere due to the large fraction of fossil fuel emissions in the Northern Hemisphere.

\subsubsection{Uncertainty associated with model resolution}

Finer model resolution is capable of reproducing small-scale meteorological conditions, which is critical to BC transport (Sato et al., 2016). We use horizontal resolution of $4^{\circ}$ lat $\times 5^{\circ}$ lon in the standard simulation and Exps. A-D because the size-resolved microphysical scheme TOMAS in Exp. D is computationally expensive. We investigate the uncertainty associated with model resolution in Exp. E by using a finer horizontal resolution of $2^{\circ}$ lat $\times 2.5^{\circ}$ lon (Fig. 4). We find that, relative to the standard simulation, $f_{\mathrm{bb}}$ in Exp. E changes by $-5 \%-5 \%$ in the 13 regions in all seasons. In most regions, the absolute change is smaller than or equal to the change in Exp. A-D, except in mid-latitude and tropical regions in Exp. A. Averaged over the whole globe, the relative change of $f_{\mathrm{bb}}$ to the standard simulation is $-1 \%$.

\subsubsection{Other uncertainties}

Carbon isotope measurements of BC sources are associated with large uncertainties. The thermal-optical protocol used 
for the carbon isotope measurements of BC produces $\sim 30 \%$ difference of observed $f_{\mathrm{bb}}$ values (Zhang et al., 2012), which is equal to or larger than the uncertainties of modeled $f_{\mathrm{bb}}$ associated with biofuel emissions north of $45^{\circ} \mathrm{N}$, the aging rate and wet scavenging discussed in Sect. 4.3.1-4.3.4. The comparison of the two sets of data in Sect. 4.1 and 4.2 is within a similar uncertainty range. In addition, we do not have carbon isotope measurements in the Southern Hemisphere to constrain the model results. Our analysis in this study is based only on model results.

In addition to the biofuel emissions discussed in Sect. 4.3.1, open fire emissions, particularly in the boreal regions, are associated with large uncertainties (Randerson et al., 2012). Konovalov et al. (2018) found that open burning emissions of Siberian fires during May to September from GFED4 is possibly underestimated by a factor of 2, constrained by satellite observations of the aerosol absorption optical depth and the aerosol extinction optical depth. However, we find that during the same season, mean atmospheric $f_{\mathrm{bb}}$ at Tiksi in Russia is overestimated by $88 \%$, indicating that open burning emissions in this region from GFED4 are possibly overestimated. This contradiction suggests that further studies are needed to better constrain the open burning emissions in boreal regions. In addition, the global fossil fuel (Bond et al., 2007) and biofuel emission inventory (Fernandes et al., 2007) used in this study are for the year 2000, and the emissions in Asia (Li et al., 2017) are for the year 2010. We estimated the $f_{\mathrm{bb}}$ from 2007 to 2013 using these constant inventories and varying open burning emissions from GFED4. The lack of inter-annual variations of BC fossil fuel and biofuel emissions also produces uncertainties, but it is difficult to quantify based on current knowledge.

\section{Conclusions}

This study sought to understand the relative contribution of fossil fuel combustion and biomass burning to global BC. We used GEOS-Chem (v11-01) driven by MERRA2 assimilated meteorological fields to simulate BC concentration from fossil fuel and biomass burning. The source apportionment results were expressed as the fraction of BC from biomass burning $\left(f_{\mathrm{bb}}\right)$. Simulated $f_{\mathrm{bb}}$ was validated against carbon isotope measurements of $\mathrm{BC}$ in the atmosphere at 65 stations across the Northern Hemisphere and for 11 snow samples over the Himalayan-Tibetan Plateau. We also investigated the uncertainties of $f_{\mathrm{bb}}$ associated with biofuel emissions, the fraction of hydrophilic BC in fresh emissions, aging time and size-resolved scavenging.

The model reproduced the mean observed atmospheric $f_{\mathrm{bb}}$ in various regions and in snow over the Himalayan-Tibetan Plateau within a factor of 2. Generally, values of atmospheric $f_{\text {bb }}$ were larger in remote regions $(33 \pm 14 \%$ in the Arctic, $39 \pm 17 \%$ over the Himalayan-Tibetan Plateau and $36 \pm 16 \%$ in southern Asia) than those in urban regions (13 $\pm 4 \%$ in
North America), indicating a larger contribution from biofuel and open burning sources in rural, developing and remote regions. $f_{\text {bb }}$ was higher in summer $(59 \%-78 \%$, varying with regions) than in winter ( $28 \%-32 \%$, varying with regions) in the Arctic, while it was higher in winter (42\%-58\%, varying with regions) and lower in summer (16\%-42\%, varying with regions) over the Himalayan-Tibetan Plateau. The simulated amplitudes of the seasonal variations were much smaller in the two regions. The seasonal variation was observed to be relatively flat in North America, eastern and southern Asia. The simulated monthly mean $f_{\mathrm{bb}}$ values in these regions agree with observations by $-45 \%-275 \%$. The Southern Hemisphere had a higher atmospheric $f_{\mathrm{bb}}$ than the Northern Hemisphere (SH: $50 \pm 11 \%$; NH: $35 \pm 14 \%$ ) due to the large fraction of open burning emissions in $\mathrm{S}$ America and Australia and large fraction of biofuel consumption in Africa. In the Northern Hemisphere, the highest $f_{\text {bb }}$ was in S Asia $(54 \pm 10 \%)$, followed by E Asia ( $41 \pm 13 \%)$, due to large biofuel consumption. In other regions, such as Europe, Canada, the US, Siberia and the Arctic, $f_{\mathrm{bb}}$ values are small (20\%-35\%, varying with regions).

Simulated $f_{\mathrm{bb}}$ was associated with uncertainties from all processes, including emissions, aging and deposition processes. We found that doubled biofuel emissions used for domestic heating north of $45^{\circ} \mathrm{N}$ resulted in a $\sim 30 \%$ increase in $f_{\mathrm{bb}}$ in Europe, Siberia and the Arctic and a $15 \%$ increase in Canada in winter. This increase reduced the discrepancy of $f_{\mathrm{bb}}$ against observations from $-63 \%$ to $-54 \%$ in Europe, suggesting that the biofuel emissions at high latitudes were underestimated by the bottom-up emission inventories. Using a higher fraction of hydrophilic BC in fresh biomass burning plumes (uncertainty simulation: $70 \%$, standard simulation: $20 \%$ ) resulted in a reduction of $f_{\mathrm{bb}}$ in summer by $-2 \%$ to $-11 \%$, with the largest reduction in Canada and Siberia, where open fires were frequent. In the standard simulation, it was assumed that $\mathrm{BC}$ in both fossil fuel and biomass burning plumes aged following an $e$-folding time of $1.15 \mathrm{~d}$. In the uncertainty simulation, we used a $4 \mathrm{~h} e$-folding lifetime for $\mathrm{BC}$ in biomass burning plumes and a linear aging rate of $1 \%$ for $\mathrm{BC}$ in fossil fuel plumes. This led to a reduction of $f_{\mathrm{bb}}$ of up to $-14 \%$ in the atmosphere. The largest reduction was in the $\mathrm{S}$ Pacific in fall (MAM) and summer (DJF) in the Southern Hemisphere. The reductions in the Antarctic $(-12 \%)$ and the Arctic $(-11 \%)$ were also large in fall, when there were large open fires in the Southern Hemisphere, and at high latitudes in the Northern Hemisphere. The size-resolved aging and scavenging scheme led to a larger increase in the fraction of hydrophilic BC in fossil fuel plumes (by $16 \% ; 0 \%-31 \%$ ) than in biomass burning plumes (by $12 \% ; 0 \%-23 \%)$. Thus atmospheric $f_{\text {bb }}$ increased in most regions during MAM (by $1 \%-14 \%$ ), SON (by 0\%-7\%) and DJF (by 1\%-12\%). Using finer model resolution produced $-5 \%-5 \%$ relative change of atmospheric $f_{\mathrm{bb}}$ in the various regions, equal to or smaller than the change caused by atmospheric processes. 
This study showed that local emissions had a larger effect on atmospheric $f_{\mathrm{bb}}$ than other atmospheric processes. As discussed in Sect. 1, most previous studies compared measured atmospheric $f_{\mathrm{bb}}$ directly with $f_{\mathrm{bb}}$ in local emissions. We confirmed this assumption but suggested considering the uncertainties associated with aging and scavenging (up to $14 \%$ ). In addition, $\mathrm{a} \sim 30 \%$ difference of isotope-based measurements of $f_{\mathrm{bb}}$ caused by the thermal-optical protocols in measuring BC should also be considered.

This study has important implications for estimating radiative forcing of global BC. Previous studies (Healy et al., 2015, and references therein) showed that BC-containing particles in open fires had no optical lensing effect. Considering the large contribution from biomass burning in S Asia, SE Asia and in the Southern Hemisphere as suggested in this study, the inclusion of lensing-related absorption enhancement in climate models for BC from both fossil fuel combustion and biomass burning sources may lead to an overestimate of the radiative forcing of global BC. Measurements of the optical properties of BC particles from different sources (fossil fuel versus biomass burning) in different regions are needed to better constrain its radiative forcing.

Data availability. The data used in this study are available from the corresponding author upon request (shxwang@tsinghua.edu.cn).

Supplement. The supplement related to this article is available online at: https://doi.org/10.5194/acp-19-11545-2019-supplement.

Author contributions. LQ and SW designed the experiments. LQ performed the simulations. LQ prepared the paper, with contributions from SW.

Competing interests. The authors declare that they have no conflict of interest.

Acknowledgements. This work was supported by Key Projects of National Key Research and Development Program of the Ministry of Science and Technology of China (2017YFC0213005), the National Natural Science Foundation of China (21625701 and 21806088), and the National Research Program for Key Issues in Air Pollution Control (DQGG0301 and DQGG0303). We thank the two reviewers for their constructive comments on the paper.

Financial support. This research has been supported by Key Projects of National Key Research and Development Program of the Ministry of Science and Technology of China (grant no. 2017YFC0213005), the National Natural Science Foundation of China (grant nos. 21625701 and 21806088), and the National
Research Program for Key Issues in Air Pollution Control (grant nos. DQGG0301 and DQGG0303).

Review statement. This paper was edited by Aijun Ding and reviewed by two anonymous referees.

\section{References}

Adams, P. J. and Seinfeld, J. H.: Predicting global aerosol size distributions in general circulation models, J. Geophys. Res.-Atmos., 107, 4370-4392, https://doi.org/10.1029/2001JD001010, 2002.

Akagi, S. K., Craven, J. S., Taylor, J. W., McMeeking, G. R., Yokelson, R. J., Burling, I. R., Urbanski, S. P., Wold, C. E., Seinfeld, J. H., Coe, H., Alvarado, M. J., and Weise, D. R.: Evolution of trace gases and particles emitted by a chaparral fire in California, Atmos. Chem. Phys., 12, 1397-1421, https://doi.org/10.5194/acp12-1397-2012, 2012.

Andersson, A., Deng, J., Du, K., Zheng, M., Yan, C., Skold, M., and Gustafsson, O.: Regionally-varying combustion sources of the January 2013 severe haze events over eastern China, Environ. Sci. Technol., 49, 2038-2043, https://doi.org/10.1021/es503855e, 2015.

Barrett, T. E., Robinson, E. M., Usenko, S., and Sheesley, R. J.: Source Contributions to Wintertime Elemental and Organic Carbon in the Western Arctic Based on Radiocarbon and Tracer Apportionment, Environ. Sci. Technol., 49, 11631-11639, https://doi.org/10.1021/acs.est.5b03081, 2015.

Bey, I., Jacob, D. J., Yantosca, R. M., Logan, J. A., Field, B., Fiore, A. M., Li, Q., Liu, H., Mickley, L. J., and Schultz, M.: Global modeling of tropospheric chemistry with assimilated meteorology: Model description and evaluation, J. Geophys. Res., 106, 23073-23095, https://doi.org/10.1029/2001JD000807, 2001.

Bond, T. C., Bhardwaj, E., Dong, R., Jogani, R., Jung, S., Roden, C., Streets, D. G., and Trautmann, N. M.: Historical emissions of black and organic carbon aerosol from energy-related combustion, 1850-2000, Global Biogeochem. Cy., 21, GB2018, https://doi.org/10.1029/2006gb002840, 2007.

Bond, T. C., Doherty, S. J., Fahey, D. W., Forster, P. M., Berntsen, T., DeAngelo, B. J., Flanner, M. G., Ghan, S., Kärcher, B., Koch, D., Kinne, S., Kondo, Y., Quinn, P. K., Sarofim, M. C., Schultz, M. G., Schulz, M., Venkataraman, C., Zhang, H., Zhang, S., Bellouin, N., Guttikunda, S. K., Hopke, P. K., Jacobson, M. Z., Kaiser, J. W., Klimont, Z., Lohmann, U., Schwarz, J. P., Shindell, D., Storelvmo, T., Warren, S. G., and Zender, C. S.: Bounding the role of black carbon in the climate system: A scientific assessment, J. Geophys. Res.-Atmos., 118, 5380-5552, https://doi.org/10.1002/jgrd.50171, 2013.

Budhavant, K., Andersson, A., Bosch, C., Kruså, M., Kirillova, E. N., Sheesley, R. J., Safai, P. D., Rao, P. S. P., and Gustafsson, Ö.: Radiocarbon-based source apportionment of elemental carbon aerosols at two South Asian receptor observatories over a full annual cycle, Environ. Res. Lett., 10, 064004, https://doi.org/10.1088/1748-9326/10/6/064004, 2015.

Chen, B., Andersson, A., Lee, M., Kirillova, E. N., Xiao, Q., Krusa, M., Shi, M., Hu, K., Lu, Z., Streets, D. G., Du, K., and Gustafsson, O.: Source forensics of black carbon 
aerosols from China, Environ. Sci. Technol., 47, 9102-9108, https://doi.org/10.1021/es401599r, 2013.

D'Andrea, S. D., Häkkinen, S. A. K., Westervelt, D. M., Kuang, C., Levin, E. J. T., Kanawade, V. P., Leaitch, W. R., Spracklen, D. V., Riipinen, I., and Pierce, J. R.: Understanding global secondary organic aerosol amount and size-resolved condensational behavior, Atmos. Chem. Phys., 13, 11519-11534, https://doi.org/10.5194/acp-13-11519-2013, 2013.

Fernandes, S. D., Trautmann, N. M., Streets, D. G., Roden, C. A., and Bond, T. C.: Global biofuel use, 1850-2000, Global Biogeochem. Cy., 21, GB2019, https://doi.org/10.1029/2006gb002836, 2007.

Giglio, L., Randerson, J. T., and van der Werf, G. R.: Analysis of daily, monthly, and annual burned area using the fourthgeneration global fire emissions database (GFED4), J. Geophys. Res.-Biogeo., 118, 317-328, https://doi.org/10.1002/jgrg.20042, 2013.

Gunthe, S. S., Rose, D., Su, H., Garland, R. M., Achtert, P., Nowak, A., Wiedensohler, A., Kuwata, M., Takegawa, N., Kondo, Y., Hu, M., Shao, M., Zhu, T., Andreae, M. O., and Pöschl, U.: Cloud condensation nuclei $(\mathrm{CCN})$ from fresh and aged air pollution in the megacity region of Beijing, Atmos. Chem. Phys., 11, 1102311039, https://doi.org/10.5194/acp-11-11023-2011, 2011.

Gustafsson, Ö., Kruså, M., Zencak, Z., Sheesley, R. J., Granat, L., Engström, E., Praveen, P., Rao, P., Leck, C., and Rodhe, H.: Brown clouds over South Asia: biomass or fossil fuel combustion?, Science, 323, 495-498, https://doi.org/10.1126/science.1164857, 2009.

He, C., Li, Q. B., Liou, K. N., Zhang, J., Qi, L., Mao, Y., Gao, M., Lu, Z., Streets, D. G., Zhang, Q., Sarin, M. M., and Ram, K.: A global 3-D CTM evaluation of black carbon in the Tibetan Plateau, Atmos. Chem. Phys., 14, 7091-7112, https://doi.org/10.5194/acp-14-7091-2014, 2014.

Healy, R. M., Wang, J. M., Jeong, C.-H., Lee, A. K. Y., Willis, M. D., Jaroudi, E., Zimmerman, N., Hilker, N., Murphy, M., Eckhardt, S., Stohl, A., Abbatt, J. P. D., Wenger, J. C., and Evans, G. J.: Light-absorbing properties of ambient black carbon and brown carbon from fossil fuel and biomass burning sources, J. Geophys. Res.-Atmos., 120, 6619-6633, https://doi.org/10.1002/2015jd023382, 2015.

Herich, H., Hueglin, C., and Buchmann, B.: A 2.5 year's source apportionment study of black carbon from wood burning and fossil fuel combustion at urban and rural sites in Switzerland, Atmos. Meas. Tech., 4, 1409-1420, https://doi.org/10.5194/amt-4-14092011, 2011.

IPCC: Climate Change 2014: Synthesis Report. Contribution of Working Groups I, II and III to the Fifth Assessment Report of the Intergovernmental Panel on Climate Change, edited by: Core Writing Team, Pachauri, R. K. and Meyer, L. A., IPCC, Geneva, Switzerland, 151 pp., 2014.

Jacobson, M. Z.: Short-term effects of controlling fossil-fuel soot, biofuel soot and gases, and methane on climate, Arctic ice, and air pollution health, J. Geophys. Res., 115, D14209, https://doi.org/10.1029/2009jd013795, 2010.

Jenk, T. M., Szidat, S., Schwikowski, M., Gäggeler, H. W., Brütsch, S., Wacker, L., Synal, H.-A., and Saurer, M.: Radiocarbon analysis in an Alpine ice core: record of anthropogenic and biogenic contributions to carbonaceous aerosols in the past (1650-1940),
Atmos. Chem. Phys., 6, 5381-5390, https://doi.org/10.5194/acp6-5381-2006, 2006.

Kodros, J. and Pierce, J.: Important global and regional differences in aerosol cloud-albedo effect estimates between simulations with and without prognostic aerosol microphysics, J. Geophys. Res.-Atmos., 122, 4003-4018, https://doi.org/10.1002/2016JD025886, 2017.

Konovalov, I. B., Lvova, D. A., Beekmann, M., Jethva, H., Mikhailov, E. F., Paris, J.-D., Belan, B. D., Kozlov, V. S., Ciais, P., and Andreae, M. O.: Estimation of black carbon emissions from Siberian fires using satellite observations of absorption and extinction optical depths, Atmos. Chem. Phys., 18, 1488914924, https://doi.org/10.5194/acp-18-14889-2018, 2018.

Lee, Y. H., Chen, K., and Adams, P. J.: Development of a global model of mineral dust aerosol microphysics, Atmos. Chem. Phys., 9, 2441-2458, https://doi.org/10.5194/acp-9-2441-2009, 2009.

Li, C., Bosch, C., Kang, S., Andersson, A., Chen, P., Zhang, Q., Cong, Z., Chen, B., Qin, D., and Gustafsson, O.: Sources of black carbon to the Himalayan-Tibetan Plateau glaciers, Nat. Commun., 7, 12574, https://doi.org/10.1038/ncomms12574, 2016.

Li, M., Zhang, Q., Kurokawa, J.-I., Woo, J.-H., He, K., Lu, Z., Ohara, T., Song, Y., Streets, D. G., Carmichael, G. R., Cheng, Y., Hong, C., Huo, H., Jiang, X., Kang, S., Liu, F., Su, H., and Zheng, B.: MIX: a mosaic Asian anthropogenic emission inventory under the international collaboration framework of the MICS-Asia and HTAP, Atmos. Chem. Phys., 17, 935-963, https://doi.org/10.5194/acp-17-935-2017, 2017.

Liu, H., Jacob, D. J., Bey, I., and Yantosca, R. M.: Constraints from $210 \mathrm{~Pb}$ and $7 \mathrm{Be}$ on wet deposition and transport in a global threedimensional chemical tracer model driven by assimilated meteorological fields, J. Geophys. Res.-Atmos., 106, 12109-12128, https://doi.org/10.1029/2000jd900839, 2001.

Ma, P.-L., Rasch, P. J., Fast, J. D., Easter, R. C., Gustafson Jr., W. I., Liu, X., Ghan, S. J., and Singh, B.: Assessing the CAM5 physics suite in the WRF-Chem model: implementation, resolution sensitivity, and a first evaluation for a regional case study, Geosci. Model Dev., 7, 755-778, https://doi.org/10.5194/gmd-7755-2014, 2014.

McMeeking, G. R., Morgan, W. T., Flynn, M., Highwood, E. J., Turnbull, K., Haywood, J., and Coe, H.: Black carbon aerosol mixing state, organic aerosols and aerosol optical properties over the United Kingdom, Atmos. Chem. Phys., 11, 9037-9052, https://doi.org/10.5194/acp-11-9037-2011, 2011.

Moteki, N., Kondo, Y., Miyazaki, Y., Takegawa, N., Komazaki, Y., Kurata, G., Shirai, T., Blake, D. R., Miyakawa, T., and Koike, M.: Evolution of mixing state of black carbon particles: Aircraft measurements over the western Pacific in March 2004, Geophys. Res. Lett., 34, L11803, https://doi.org/10.1029/2006g1028943, 2007.

Mouteva, G. O., Randerson, J. T., Fahrni, S. M., Bush, S. E., Ehleringer, J. R., Xu, X., Santos, G. M., Kuprov, R., Schichtel, B. A., and Czimczik, C. I.: Using radiocarbon to constrain black and organic carbon aerosol sources in Salt Lake City, J. Geophys. Res.-Atmos., 122, 9843-9857, https://doi.org/10.1002/2017jd026519, 2017.

Park, R. J., Jacob, D. J., Chin, M., and Martin, R. V.: Sources of carbonaceous aerosols over the United States and implications for natural visibility, J. Geophys. Res.-Atmos., 108, 4355, https://doi.org/10.1029/2002jd003190, 2003. 
Park, R. J., Jacob, D. J., Palmer, P. I., Clarke, A. D., Weber, R. J., Zondlo, M. A., Eisele, F. L., Bandy, A. R., Thornton, D. C., and Sachse, G. W.: Export efficiency of black carbon aerosol in continental outflow: Global implications, J. Geophys. Res.-Atmos., 110, D11205, https://doi.org/10.1029/2004jd005432, 2005.

Petters, M. D. and Kreidenweis, S. M.: A single parameter representation of hygroscopic growth and cloud condensation nucleus activity, Atmos. Chem. Phys., 7, 1961-1971, https://doi.org/10.5194/acp-7-1961-2007, 2007.

Pierce, J. R., Chen, K., and Adams, P. J.: Contribution of primary carbonaceous aerosol to cloud condensation nuclei: processes and uncertainties evaluated with a global aerosol microphysics model, Atmos. Chem. Phys., 7, 5447-5466, https://doi.org/10.5194/acp-7-5447-2007, 2007.

Qi, L., Li, Q., He, C., Wang, X., and Huang, J.: Effects of the Wegener-Bergeron-Findeisen process on global black carbon distribution, Atmos. Chem. Phys., 17, 7459-7479, https://doi.org/10.5194/acp-17-7459-2017, 2017a.

Qi, L., Li, Q., Henze, D. K., Tseng, H.-L., and He, C.: Sources of springtime surface black carbon in the Arctic: an adjoint analysis for April 2008, Atmos. Chem. Phys., 17, 9697-9716, https://doi.org/10.5194/acp-17-9697-2017, 2017b.

Qi, L., Li, Q., Li, Y., and He, C.: Factors controlling black carbon distribution in the Arctic, Atmos. Chem. Phys., 17, 1037-1059, https://doi.org/10.5194/acp-17-1037-2017, 2017c.

Randerson, J. T., Chen, Y., van der Werf, G. R., Rogers, B. M., and Morton, D. C.: Global burned area and biomass burning emissions from small fires, J. Geophys. Res.-Biogeo., 117, G04012, https://doi.org/10.1029/2012jg002128, 2012.

Reddy, C. M., Pearson, A., Xu, L., McNichol, A. P., Benner, B. A., Wise, S. A., Klouda, G. A., Currie, L. A., and Eglinton, T. I.: Radiocarbon as a tool to apportion the sources of polycyclic aromatic hydrocarbons and black carbon in environmental samples, Environ. Sci. Technol., 36, 1774-1782, https://doi.org/10.1021/es011343f , 2002.

Sahu, L. K., Kondo, Y., Moteki, N., Takegawa, N., Zhao, Y., Cubison, M. J., Jimenez, J. L., Vay, S., Diskin, G. S., Wisthaler, A., Mikoviny, T., Huey, L. G., Weinheimer, A. J., and Knapp, D. J.: Emission characteristics of black carbon in anthropogenic and biomass burning plumes over California during ARCTAS-CARB 2008, J. Geophys. Res.-Atmos., 117, D16302, https://doi.org/10.1029/2011jd017401, 2012.

Samset, B. H., Myhre, G., Schulz, M., Balkanski, Y., Bauer, S., Berntsen, T. K., Bian, H., Bellouin, N., Diehl, T., Easter, R. C., Ghan, S. J., Iversen, T., Kinne, S., Kirkevåg, A., Lamarque, J.-F., Lin, G., Liu, X., Penner, J. E., Seland, Ø., Skeie, R. B., Stier, P., Takemura, T., Tsigaridis, K., and Zhang, K.: Black carbon vertical profiles strongly affect its radiative forcing uncertainty, Atmos. Chem. Phys., 13, 2423-2434, https://doi.org/10.5194/acp13-2423-2013, 2013.

Samset, B. H., Myhre, G., Herber, A., Kondo, Y., Li, S.-M., Moteki, N., Koike, M., Oshima, N., Schwarz, J. P., Balkanski, Y., Bauer, S. E., Bellouin, N., Berntsen, T. K., Bian, H., Chin, M., Diehl, T., Easter, R. C., Ghan, S. J., Iversen, T., Kirkevåg, A., Lamarque, J.F., Lin, G., Liu, X., Penner, J. E., Schulz, M., Seland, Ø., Skeie, R. B., Stier, P., Takemura, T., Tsigaridis, K., and Zhang, K.: Modelled black carbon radiative forcing and atmospheric lifetime in AeroCom Phase II constrained by aircraft observations, Atmos.
Chem. Phys., 14, 12465-12477, https://doi.org/10.5194/acp-1412465-2014, 2014.

Sato, Y., Miura, H., Yashiro, H., Goto, D., Takemura, T., Tomita, H., and Nakajima, T.: Unrealistically pristine air in the Arctic produced by current global scale models, Sci. Rep., 6, 26561, https://doi.org/10.1038/srep26561, 2016.

Schwarz, J. P., Gao, R. S., Spackman, J. R., Watts, L. A., Thomson, D. S., Fahey, D. W., Ryerson, T. B., Peischl, J., Holloway, J. S., Trainer, M., Frost, G. J., Baynard, T., Lack, D. A., de Gouw, J. A., Warneke, C., and Del Negro, L. A.: Measurement of the mixing state, mass, and optical size of individual black carbon particles in urban and biomass burning emissions, Geophys. Res. Lett., 35, L13810, https://doi.org/10.1029/2008gl033968, 2008.

Shiraiwa, M., Kondo, Y., Moteki, N., Takegawa, N., Miyazaki, Y., and Blake, D. R.: Evolution of mixing state of black carbon in polluted air from Tokyo, Geophys. Res. Lett., 34, L16803, https://doi.org/10.1029/2007gl029819, 2007.

Stohl, A., Klimont, Z., Eckhardt, S., Kupiainen, K., Shevchenko, V. P., Kopeikin, V. M., and Novigatsky, A. N.: Black carbon in the Arctic: the underestimated role of gas flaring and residential combustion emissions, Atmos. Chem. Phys., 13, 8833-8855, https://doi.org/10.5194/acp-13-8833-2013, 2013.

Subramanian, R., Kok, G. L., Baumgardner, D., Clarke, A., Shinozuka, Y., Campos, T. L., Heizer, C. G., Stephens, B. B., de Foy, B., Voss, P. B., and Zaveri, R. A.: Black carbon over Mexico: the effect of atmospheric transport on mixing state, mass absorption cross-section, and BC / CO ratios, Atmos. Chem. Phys., 10, 219-237, https://doi.org/10.5194/acp-10-219-2010, 2010.

Szidat, S., Jenk, T. M., Synal, H.-A., Kalberer, M., Wacker, L., Hajdas, I., Kasper-Giebl, A., and Baltensperger, U.: Contributions of fossil fuel, biomass-burning, and biogenic emissions to carbonaceous aerosols in Zurich as traced by 14C, J. Geophys. Res., 111, D07206, https://doi.org/10.1029/2005JD006590, 2006.

Szidat, S., Ruff, M., Perron, N., Wacker, L., Synal, H.-A., Hallquist, M., Shannigrahi, A. S., Yttri, K. E., Dye, C., and Simpson, D.: Fossil and non-fossil sources of organic carbon (OC) and elemental carbon (EC) in Göteborg, Sweden, Atmos. Chem. Phys., 9, 1521-1535, https://doi.org/10.5194/acp-9-1521-2009, 2009.

van der Werf, G. R., Randerson, J. T., Giglio, L., Collatz, G. J., Mu, M., Kasibhatla, P. S., Morton, D. C., DeFries, R. S., Jin, Y., and van Leeuwen, T. T.: Global fire emissions and the contribution of deforestation, savanna, forest, agricultural, and peat fires (1997-2009), Atmos. Chem. Phys., 10, 11707-11735, https://doi.org/10.5194/acp-10-11707-2010, 2010.

Wang, Q., Jacob, D. J., Fisher, J. A., Mao, J., Leibensperger, E. M., Carouge, C. C., Le Sager, P., Kondo, Y., Jimenez, J. L., Cubison, M. J., and Doherty, S. J.: Sources of carbonaceous aerosols and deposited black carbon in the Arctic in winter-spring: implications for radiative forcing, Atmos. Chem. Phys., 11, 1245312473, https://doi.org/10.5194/acp-11-12453-2011, 2011.

Winiger, P., Andersson, A., Yttri, K. E., Tunved, P., and Gustafsson, O.: Isotope-Based Source Apportionment of EC Aerosol Particles during Winter High-Pollution Events at the Zeppelin Observatory, Svalbard, Environ. Sci. Technol., 49, 11959-11966, https://doi.org/10.1021/acs.est.5b02644, 2015.

Winiger, P., Andersson, A., Eckhardt, S., Stohl, A., and Gustafsson, Ö.: The sources of atmospheric black carbon at a European gateway to the Arctic, Nat. Commun., 7, 12776, https://doi.org/10.1038/ncomms12776, 2016. 
Winiger, P., Andersson, A., Eckhardt, S., Stohl, A., Semiletov, I. P., Dudarev, O. V., Charkin, A., Shakhova, N., Klimont, Z., Heyes, C., and Gustafsson, O.: Siberian Arctic black carbon sources constrained by model and observation, P. Natl. Acad. Sci. USA, 114, E1054-E1061, https://doi.org/10.1073/pnas.1613401114, 2017.

Yamamoto, N., Muramoto, A., Yoshinaga, J., Shibata, K., Endo, M., Endo, O., Hirabayashi, M., Tanabe, K., Goto, S., and Yoneda, M.: Comparison of carbonaceous aerosols in Tokyo before and after implementation of diesel exhaust restrictions, Environ. Sci. Technol., 41, 6357-6362, https://doi.org/10.1021/acs.est.5b02644, 2007.

Zhang, Y. L., Perron, N., Ciobanu, V. G., Zotter, P., Minguillón, M. C., Wacker, L., Prévôt, A. S. H., Baltensperger, U., and Szidat, S.: On the isolation of OC and EC and the optimal strategy of radiocarbon-based source apportionment of carbonaceous aerosols, Atmos. Chem. Phys., 12, 10841-10856, https://doi.org/10.5194/acp-12-10841-2012, 2012.
Zhang, Y.-L., Huang, R.-J., El Haddad, I., Ho, K.-F., Cao, J.-J., Han, Y., Zotter, P., Bozzetti, C., Daellenbach, K. R., Canonaco, F., Slowik, J. G., Salazar, G., Schwikowski, M., Schnelle-Kreis, J., Abbaszade, G., Zimmermann, R., Baltensperger, U., Prévôt, A. S. H., and Szidat, S.: Fossil vs. non-fossil sources of fine carbonaceous aerosols in four Chinese cities during the extreme winter haze episode of 2013, Atmos. Chem. Phys., 15, 1299-1312, https://doi.org/10.5194/acp-15-1299-2015, 2015. 